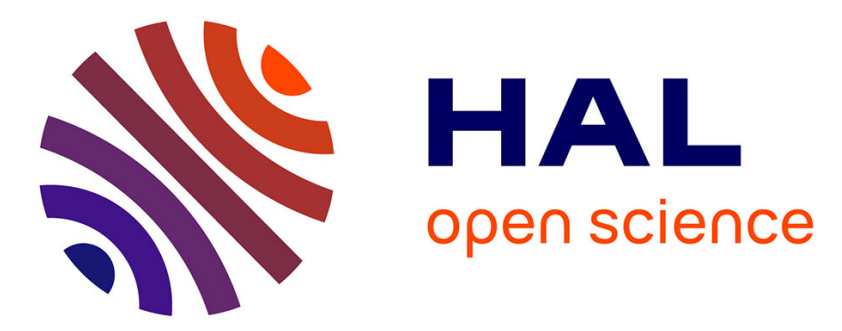

\title{
Contribution of computational model for assessment of heart tissue local stress caused by suture in LVAD implantation
}

Antoine Chalon, Julien Favre, Boris Piotrowski, V. Landmann, David Grandmougin, Juan Pablo Maureira, Pascal Laheurte, Nguyen Tran

\section{To cite this version:}

Antoine Chalon, Julien Favre, Boris Piotrowski, V. Landmann, David Grandmougin, et al.. Contribution of computational model for assessment of heart tissue local stress caused by suture in LVAD implantation. Journal of the mechanical behavior of biomedical materials, 2018, 82, pp.291-298. 10.1016/j.jmbbm.2018.03.032 . hal-02272692

\section{HAL Id: hal-02272692 \\ https://hal.science/hal-02272692}

Submitted on 28 Aug 2019

HAL is a multi-disciplinary open access archive for the deposit and dissemination of scientific research documents, whether they are published or not. The documents may come from teaching and research institutions in France or abroad, or from public or private research centers.
L'archive ouverte pluridisciplinaire HAL, est destinée au dépôt et à la diffusion de documents scientifiques de niveau recherche, publiés ou non, émanant des établissements d'enseignement et de recherche français ou étrangers, des laboratoires publics ou privés. 


\title{
Contribution of computational model for assessment of heart tissue local stress caused by suture in LVAD implantation
}

\author{
A. Chalon ${ }^{\mathrm{a}, \mathrm{b}, \mathrm{c}, *}$, J. Favre $^{\mathrm{d}}$, B. Piotrowski ${ }^{\mathrm{c}}$, V. Landmann ${ }^{\mathrm{c}}$, D. Grandmougin ${ }^{\mathrm{a}}$, J-P. Maureira ${ }^{\mathrm{a}}$, \\ P. Laheurte ${ }^{\mathrm{c}}, \mathrm{N}$. Tran ${ }^{\mathrm{a}, \mathrm{b}}$ \\ a Ecole de Chirurgie Nancy-Lorraine, HVL, Université de Lorraine, Nancy, France \\ ${ }^{\mathrm{b}}$ UMR INSERM 1116 DCAC, Nancy, France \\ c Université de Lorraine, CNRS, Arts et Métiers ParisTech, LEM3, F-57000 Metz, France \\ d Laboratoire Georges Friedel, ENSM-SE, UMR CNRS 5307, Saint-Etienne, France
}

\begin{abstract}
A B S T R A C T
Study: Implantation of a Left Ventricular Assist Device (LVAD) may produce both excessive local tissue stress and resulting strain-induced tissue rupture that are potential iatrogenic factors influencing the success of the surgical attachment of the LVAD into the myocardium. By using a computational simulation compared to mechanical tests, we sought to investigate the characteristics of stress-induced suture material on porcine myocardium.

Methods: Tensile strength experiments $(\mathrm{n}=8)$ were performed on bulk left myocardium to establish a hyperelastic reduced polynomial constitutive law. Simultaneously, suture strength tests on left myocardium $(n=6)$ were performed with a standard tensile test setup. Experiments were made on bulk ventricular wall with a single U-suture (polypropylene 3-0) and a PTFE pledget. Then, a Finite Element simulation of a LVAD suture case was performed. Strength versus displacement behavior was compared between mechanical and numerical experiments. Local stress fields in the model were thus analyzed.

Results: A strong correlation between the experimental and the numerical responses was observed, validating the relevance of the numerical model. A secure damage limit of $100 \mathrm{kPa}$ on heart tissue was defined from mechanical suture testing and used to describe numerical results. The impact of suture on heart tissue could be accurately determined through new parameters of numerical data (stress diffusion, triaxiality stress). Finally, an ideal spacing between sutures of $2 \mathrm{~mm}$ was proposed.

Conclusion: Our computational model showed a reliable ability to provide and predict various local tissue stresses created by suture penetration into the myocardium. In addition, this model contributed to providing valuable information useful to design less traumatic sutures for LVAD implantation. Therefore, our computational model is a promising tool to predict and optimize LVAD myocardial suture.
\end{abstract}

\section{Introduction}

Cardiovascular diseases remain the leading cause of mortality, and heart failure (HF) therefore represents a major health and economic burden as well as a challenge in therapeutic management (Go et al., 2014; Bui et al., 2011; Braunwald, 2013). For a large proportion of patients, a heart transplant is not available and pharmacological treatments are not efficient enough. In these cases, implantation of ventricular assist devices (VADs) is considered either as a lifeprolonging therapy, a bridge to transplant or, in some cases, as a definitive implantation (Heidenreich et al., 2013; Seyfarth et al., 2008).

Over the past few years, LVAD has certainly shown clear properties in improving quality of life (Rogers et al., 2010; Stewart and Givertz, 2012), however, attachment of the device to the heart remains a debated and critical issue (Bernhardt et al., 2015; Charitos and Sievers, 2010). In order to minimize the risk of myocardial tearing and bleeding the device is fixed and secured to the ventricle with U-suture using polytetrafluoroethylene (PTFE) pledgets to spread and reduce the mechanical stress. Despite numerous improvements, debate about the risk and optimization of LVAD attachment is still ongoing (Bernhardt et al., 2015; Hanke et al., 2016). The LVAD surgical implantation remains a complex procedure that requires good knowledge of the technique and great dexterity. Among all the aspects of this procedure, the suture of the device to the myocardium is crucial because it might impact both 


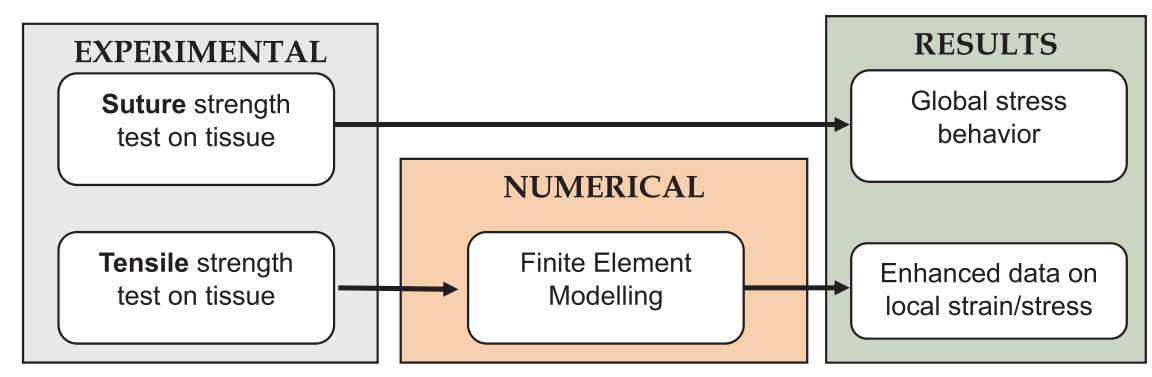

Fig. 1. Schematic representation of global study strategy.

acute and long-term success of the LVAD therapy. That is why the study of the myocardium in response to stress and, in this particular case, to suture materials still presents great interest as a solution to analyze and optimize LVAD suture.

The modeling of the left heart and related mechanical behaviors of heart muscle in response to multi-axial traction, compression and shear stress remains a challenging topic due to the complexity and specific mechanical characteristics of the myocardium (Humphrey et al., 1990a). Biaxial and shearing explorations have been widely used to investigate such parameters, but accurate data are somewhat impaired by the method of performing the tissue gripping and the nature of heart samples. In papillary muscle, a highly specific heart structure, some authors have however found good correlation between uniaxial tensile strength response and hyperelastic models (Humphrey et al., 1990b; Hassan et al., 2012). Recently, numerical models for heart simulations (Nash and Hunter, 2000; Baillargeon et al., 2014; Smith et al., 2011; Horowitz et al., 1986; Sermesant et al., 2006) have been developed to describe myocardial tissue with multiple levels of complexity (Pinto and Fung, 1973). Most of the models provide an exhaustive description with a large number of parameters. However, these models, which are frequently performed on a specific area of heart tissue, are rather complex to use and hard to implement in terms of calculation time (Stevens and Hunter, 2003; Sommer, 2013; Huyghe et al., 1991; Lin and Yin, 1998). Nonetheless, the use of numerical simulation and more precisely of finite element analysis (FEA) seems of great interest. We hypothesize that numerical data on the stress fields near myocardial sutures may be used to determine minimal spacing between sutures to prevent excessive stress concentrations.

To our knowledge, no previous study has reported data relative to a numerical model adapted to myocardial suture.

On the other hand, the literature about suture materials has provided only generic data with global stress studies (Naleway et al., 2015; Paez et al., 1994). Again, no study on the impact of suture material on the myocardium has been found.

In this paper, we first intended to establish an isotropic constitutive law with a small number of reliable parameters from uniaxial tensile tests. Following a similar methodology to that which was used to study tendon suturing (Rawson et al., 2015), we hypothesized that numerical simulation using finite element analyses (F.E.A.) of sutures may provide new data to evaluate the anchoring of a device into the myocardium. Moreover, recent communications from the U.S. Food and Drug Administration (FDA) have confirmed a firm intent to include simulation in the development cycle of biomedical devices (Morrison et al., 2017; Malinauskas et al., 2017). This kind of analysis is cost-effective and allows a drastic reduction in the number of animals required.

The study herein describes a numerical model for left myocardial suture evaluation based on:

- Characterization of mechanical properties of the left passive myocardium by uniaxial tensile strength testing.

- Evaluation of mechanical resistance of a U-suture in left myocardium samples.

- Setup and validation of a finite element model (FE) for left myocardial suture study.

With the help of the model hereby presented, we aim to provide a numerical tool for the assessment of stress concentrations caused by suture into the left ventricle. The investigation of the stress fields should allow us to define a numerical threshold for suture spacing.

\section{Materials and methods}

\subsection{Study design}

This study proposed to investigate local stresses around the sutures following a myocardial suture as described for a LVAD implantation. Following a similar methodology to that reported by Rawson et al. (2015), both experimental and numerical investigations were simultaneously conducted to show the limitations of a single experimental evaluation and highlight the contribution of a numerical model to improve the reliability of these investigations. To setup the Finite Element Model (FEM), myocardium uniaxial characterizations were performed. A synthetic diagram of this strategy is presented in Fig. 1.

\subsection{Harvest and shaping of ventricular wall samples}

Pig hearts were surgically harvested at the School of Surgery using the facilities of operating rooms (OR) under the supervision of staff certified in experimental animal surgery (authorization number 54-96, Dr. Nguyen Tran). All procedures followed the NIH guidelines of the Guide for the Care and Use of Laboratory Animals and were in accordance with French legislation (Ministerial Authorization $n^{\circ}$ C54-547-5). Cardiac explantation was performed on animals previously anesthetized and used for training purpose in order to follow the Reduction rule provided by the 3 R's guidelines (Bratcher and Reinhard, 2015). Precautions were taken to preserve myocardial integrity as well as mechanical properties.

A total of 14 pigs (aged 3-5 months, weighing $45 \pm 5 \mathrm{~kg}$ ) were premedicated with midazolam $(1 \mathrm{mg} / \mathrm{kg}$, im) and ketamine $(10-20 \mathrm{mg} /$ $\mathrm{kg}$, im). Anesthesia was induced with propofol (100 mg, iv) and maintained $(30 \mathrm{mg} / \mathrm{h}$, iv) during the whole procedure. Analgesia was obtained by administration of sufentanyl after catheterization of the right internal jugular vein.

Following surgical guidelines (Humphrey et al., 1990b), a median sternotomy was performed, and the pericardium was opened. Then, the ascending aorta was cross-clamped, and the heart was arrested with a $50-100 \mathrm{ml}$ intracardiac injection of a solution with high potassium concentration. Hearts were harvested and rinsed immediately with cold Krebs-Henseleit buffer $\left(4^{\circ} \mathrm{C}\right)$ to remove blood and clots before complete immersion in this solution. Harvesting procedures were systematically performed less than $4 \mathrm{~h}$ before mechanical assessment.

Left myocardial tissue $\left(20 \times 30 \mathrm{~mm}^{2}\right)$ was excised with transmural incisions through the anterior aspects of the left and right ventricles as seen in Fig. 2. In order to closely simulate the surgical features of a LVAD implantation and minimize the influence of wall thickness discrepancies, a senior cardiac surgeon validated the location of ventricular sampling sites. For each heart, one sample of left ventricle was 


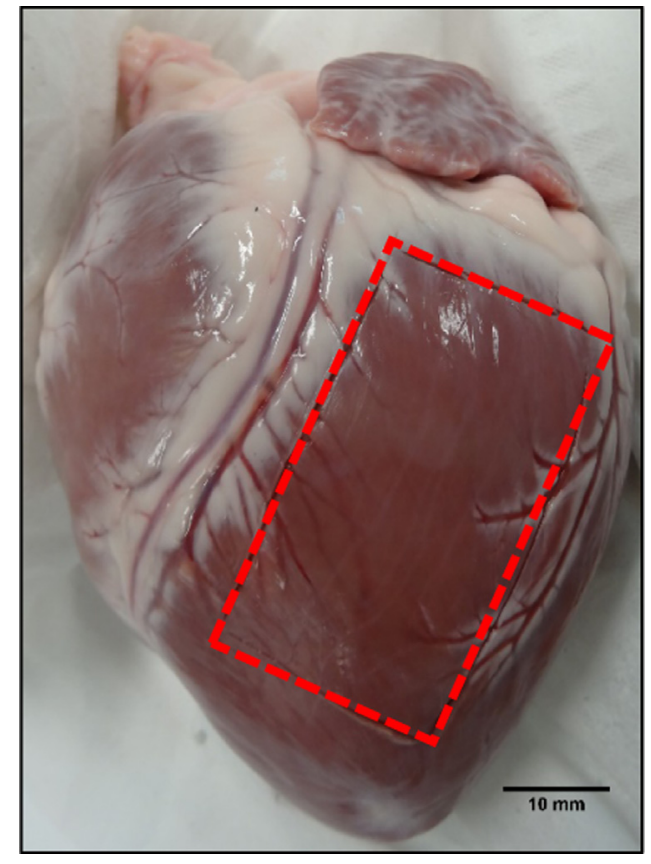

Fig. 2. Left ventricular sample harvested from fresh porcine heart.

obtained. For suture testing $(n=6)$, raw samples were prepared with suture material.

For tissue characterization ( $\mathrm{n}=8$ ), the heart section of interest was trimmed and shaped to obtain a parallelepiped of $10 \times 30 \times 5 \mathrm{~mm}^{3}$ in line with previously published studies (Forsell and Gasser, 2011). Specific shape was designed to get proper tissular gripping and ensure that rupture would occur in the center of the sample and not beside the clamps.

\subsection{Testing apparatus and methodology}

A tensile strength testing device ( $10 \mathrm{kN}$, ERIKSEN, Germany) was used with a constraint gauge for the strength measurement and a Linear Variable Differential Transformer (LVDT) to assess the displacement (Gefram, Italia). Fig. 3 illustrates a schematic view of both configurations selected for this study. Trials were performed at a speed of $10 \mathrm{~mm} /$ minute, which corresponded to a strain rate $\dot{\varepsilon}$ of $0.006 \mathrm{~s}^{-1}$ to preserve relevance with the size of the samples as reported in similar publications (Forsell and Gasser, 2011).

Both parameters were recorded in real-time with a National Instruments acquisition card and LabVIEW software (National Instruments, Switzerland) with a custom LabVIEW application (VI) designed for this experiment with 50 acquisitions per second.

Both tensile and suture strength testing were performed on this device with differences in the clamping method, using (Fig. 3a) two metal plates fixed to each other for tensile testing and (Fig. 3b) fastened with suture material. Methyl cyanoacrylate glue was used between clamps and samples to prevent slipping.

The main goal of these trials was to collect uniaxial stress-strain data for calibration of the model and setup of FE simulation. Published studies on a large panel of soft biological tissues have investigated on uniaxial experiments (Baillargeon et al., 2014; Bratcher and Reinhard, 2015; Forsell and Gasser, 2011). Heterogeneous results were reported, consecutive to variable methodologies. Therefore, we decided to carry out dedicated experiments to ensure consistency within this study.

Mean value of the thickness of each sample was used for this study, since ventricular thickness was not uniform with the transventricular samples.

In order to collect comparable data from all samples, a specific protocol for the surgical sutures was designed. The distance between entry points of the U-suture through the piece of medical grade PTFE pledget $\left(15 \times 25 \times 0.5 \mathrm{~mm}^{3}\right)$ and the free border of the sample was set to $10 \mathrm{~mm}$. Stitches were performed using a 3-0 non-absorbable polypropylene suture.

Depth of the sutures within the left ventricular myocardium resulted from the achievable distance run by the needle (about $10 \mathrm{~mm}$ deep).

Once prepared with the standardized pledgeted U-suture, the sample was positioned and secured with five ligature knots. A symmetrical positioning was adopted to avoid artefacts and excessive stress that might result from embedding the sample in a fixed jaw.

\subsection{Finite Element Model (FEM) setup}

Finite Element Modeling (FEM) and simulation were performed using Abaqus 6.14-5 (SIMULIA, Dassault Systèmes, USA) Explicit Package. For time optimization purpose, only a quarter of the experimental trial was simulated, then two symmetry planes were used along the $\mathrm{Z}$ and Y-axis. Model size was set to $15 \times 25 \times 15 \mathrm{~mm}^{3}$ for the myocardium and to $12.5 \times 15 \times 0.5 \mathrm{~mm}^{3}$ for the pledget (Fig. $4 \mathrm{a}$ and b). Suture diameter was set to $0.245 \mathrm{~mm}$, corresponding to the 3-0 polypropylene suture (Naleway et al., 2015), typical suture material used in the operating room. An overall displacement of $25 \mathrm{~mm}$ was imposed at the top of the suture (Fig. $4 \mathrm{~b}$ ).

Myocardium density was set to $1.053 \mathrm{~g} / \mathrm{ml}$ following the methodology used in several publications on either rats (Vinnakota and Bassingthwaighte, 2004) or human (Katz et al., 1988). Following data from the literature (ASM International, 2009), the pledget was setup as an elastic material with a density of $2 \mathrm{~g} / \mathrm{cm}^{3}$ and a Young Modulus of $550 \mathrm{MPa}$. Suture wire material data were extracted from the literature (Naleway et al., 2015), density was set to $0.403 \mathrm{~g} / \mathrm{cm}^{3}$ and Young Modulus to $745.6 \mathrm{MPa}$.

A hyperelastic isotropic material was used to describe myocardium behavior and its parameters were computed from myocardium tensile test. General contact formulation between wire and heart tissue was setup with a 0.005 friction coefficient based on the work of Rawson et al. (2015). Myocardium and PTFE pledget were tied to simplify model contact.

PTFE Pledget and Polypropylene suture were meshed using respectively 229 and 264 C3D8R hexahedral elements. Left ventricle myocardium was ideally meshed with hexahedral elements. The part was split in three domains, the external bulk myocardium (5460 C3D8R elements), the internal contact sheath (1480 C3D8R elements) and an intermediate domain. The latter pecific volume was meshed using tetrahedral elements $(11,019$ C3D4) was to be used to link hexahedral domains (Fig. 4c). The internal sheath was created to optimize contact handling inside the simulation. Mesh convergence analysis was performed to ensure the accuracy of the simulation results. An increase of mesh densities of about 100\% (number of elements), the maximum relative error on predicted force was found to be lower than $2 \%$.

\subsection{Calculation, fit and statistical analysis}

Displacement and strength were collected from uniaxial tensile strength tests then converted to engineering and then true stress/strain curves when applicable. Numerical stress results were analyzed using equivalent Von Mises stress formulation.

Parameter fitting was performed using Abaqus Evaluate Toolbox. This specific tool was able to optimize parameters for several hyperelastic material laws and to choose the most stable and accurate behavior. The rupture strength (rupture point) was defined as the maximum recorded strength. Therefore, all data beyond the rupture point were excluded (or withdrawn).

Correlation between left ventricular thickness and rupture strength was calculated with GraphPad Prism (GraphPad Software, San Diego, California US). 

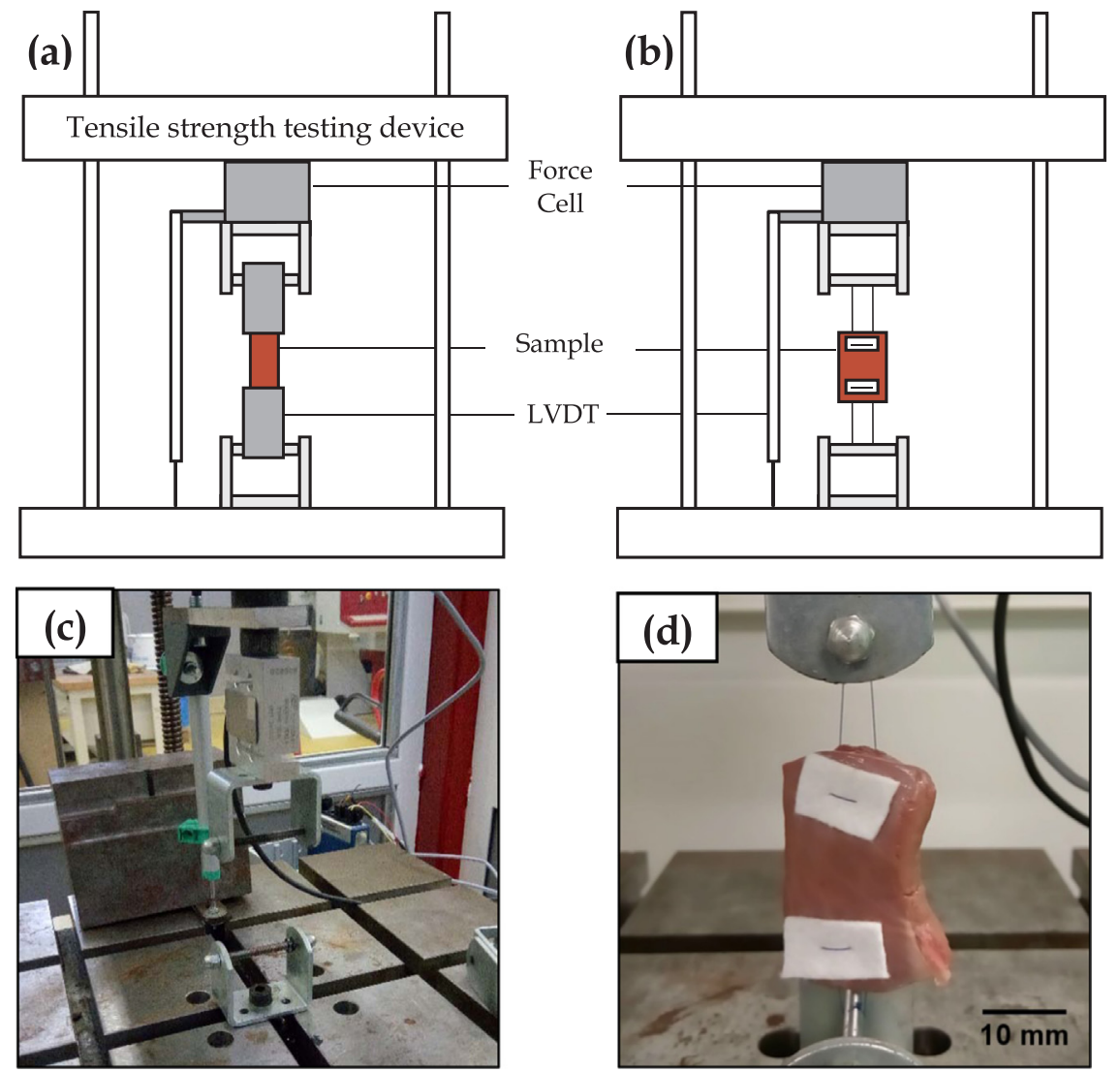

Fig. 3. Schematic view (not to scale) of experimental apparatus for (a) tensile test and (b) suture test. (c) Global view of apparatus before sample setup. (d) Sample view prior to loading.

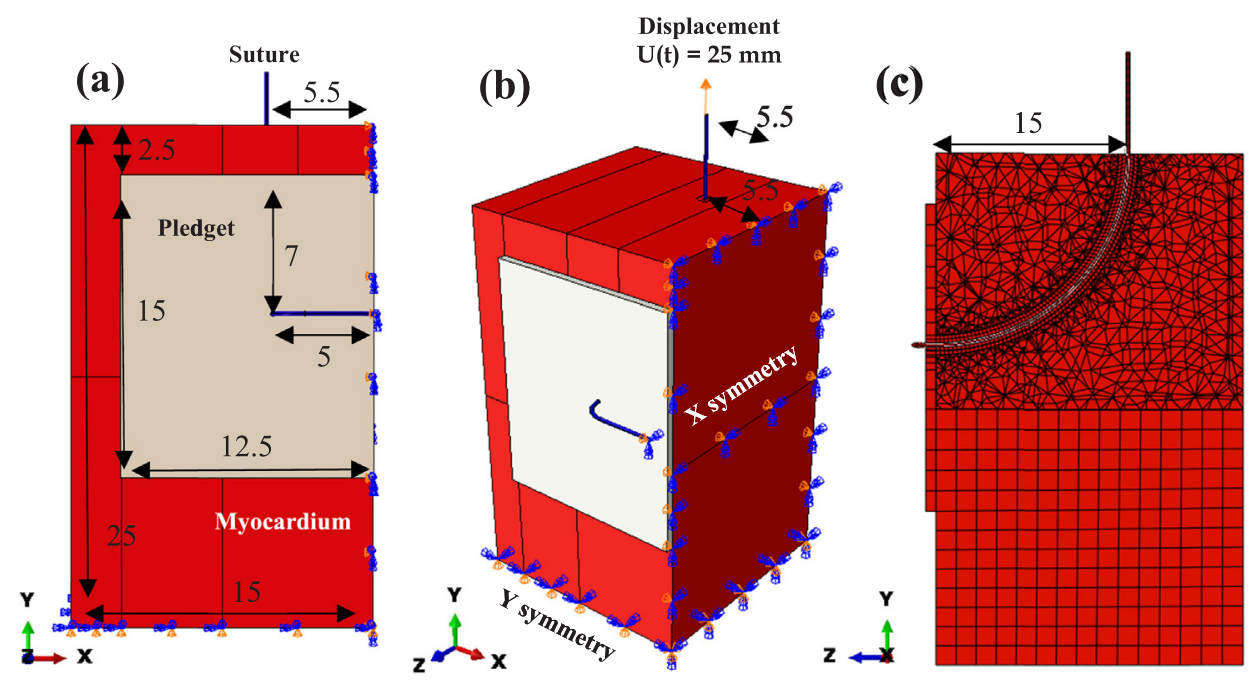

Fig. 4. Setup of the FE model with (a) dimensions in millimeters, (b) boundary conditions and load and (c) mesh.

Numerical data from simulation were obtained using Abaqus Toolboxes and Python custom scripts.

\section{Results}

\subsection{Hyperelastic numerical behavior}

Experimental curves obtained by tensile tests are illustrated on Fig. 5a. The overall behavior of the left ventricle material was hyperelastic and led to progressive rupture for stress above $100 \mathrm{kPa}$. The dataset showed some variability due to the stochastic nature of biological specimens. However, global behavior was found to be very similar, and a mean trend can be deduced. Each curve was fitted by a second order polynomial equation $\sigma=a \cdot \varepsilon^{2}+b \cdot \varepsilon$.

Among the available hyperelastic material laws, the reduced polynomial formulation (Table 1.) is found to provide numerical stability of the model at all strains. As illustrated on Fig. 5b, this specific hyperelastic law shows a perfect match with the previously computed mean curve. Parameters of the constitutive law are summarized in Table 1.

The onset of sample damage starts for a von Mises stress above $150 \mathrm{kPa}$ as shown on Fig. 5.a. With a safety factor of 1.5, a statistical rupture threshold for the material was defined at $100 \mathrm{kPa}$ (Fig. 5.a) as a 

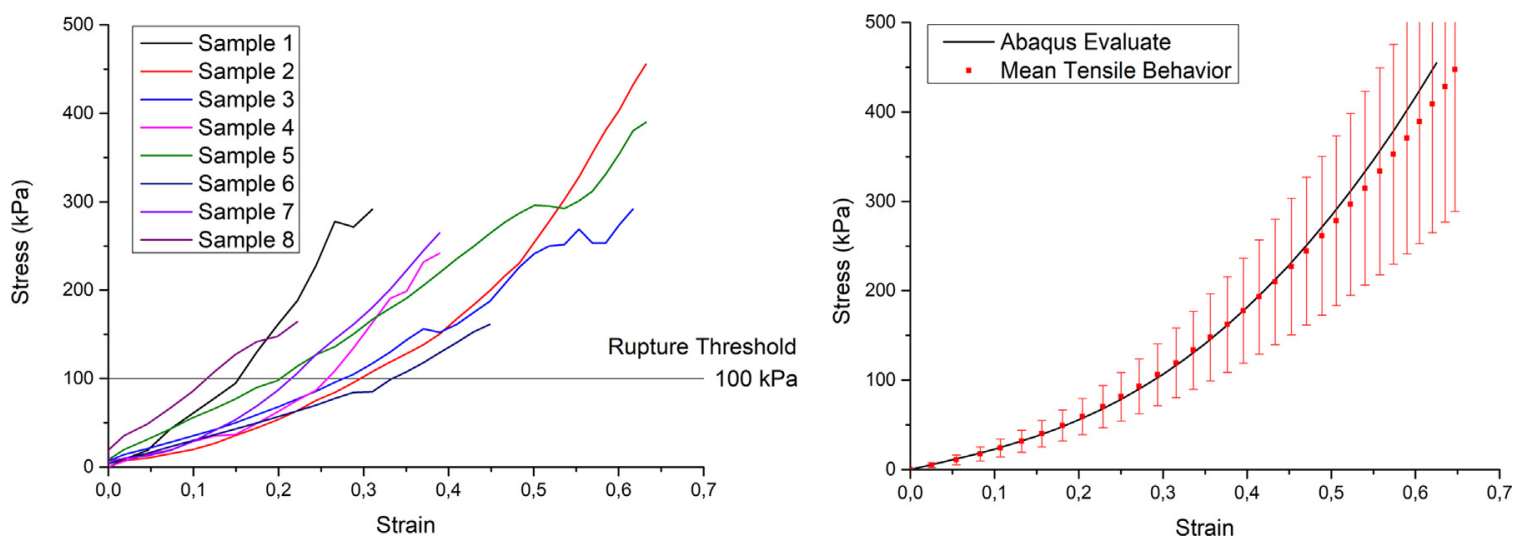

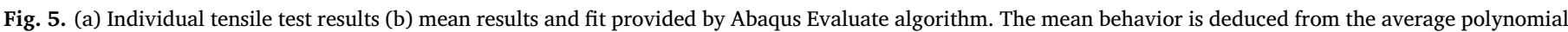
parameters (red dots). Red bars illustrate the standard deviation over a and b parameters. The mean curve is used to describe the statistical average subject.

Table 1

Reduced polynomial parameters extracted from experimental tensile tests.

\begin{tabular}{lllll}
\hline $\begin{array}{l}\text { Equation } \\
(\text { with } \mathrm{N}=2)\end{array}$ & $\mathrm{U}=\sum_{\mathrm{i}=1}^{\mathrm{N}} \mathrm{C}_{\mathrm{i} 0}\left(\overline{\mathrm{I}}_{1}-3\right)^{\mathrm{i}}+\sum_{\mathrm{i}=1}^{\mathrm{N}} \frac{1}{\mathrm{D}_{\mathrm{i}}}\left(\mathrm{J}_{\mathrm{el}}-1\right)^{2 \mathrm{i}}$ & & \\
\hline Parameters & $\mathrm{C}_{10}(\mathrm{MPa})$ & $\mathrm{C}_{20}(\mathrm{MPa})$ & $\mathrm{D}_{1}$ & $\mathrm{D}_{2}$ \\
Value & 0.0514 & 0.0419 & 0.98 & 0 \\
\hline
\end{tabular}

limit beyond which rupture may statistically happen.

\subsection{Mechanical study of a left ventricle U-suture}

Suture strength testing was performed on six harvested pig hearts. An example of load-displacement curve from these tests was plotted in Fig. 6a. The overall trend presents a hyperelastic profile. Unlike standard tensile strength tests, it has not been possible to use stress versus strain curves due to the clamping method leading to a highly heterogeneous stress field. On the left of the marker, force increases uniformly with displacement. Beyond the marker, previous hyperelastic behavior was altered by the occurrence of tissue damage.

This led to the rupture of the myocardium sample at the maximumrecorded force. Thickness and rupture strength results for all samples are summarized in Table 2.

The results from left ventricle sample suture testing have shown a mean rupture strength is $15.43 \pm 3.658 \mathrm{~N}$.

Correlation test between thickness and rupture strength has shown a positive relationship between these variables with a $R^{2}$ of 0.7131 ,

\section{(a)}

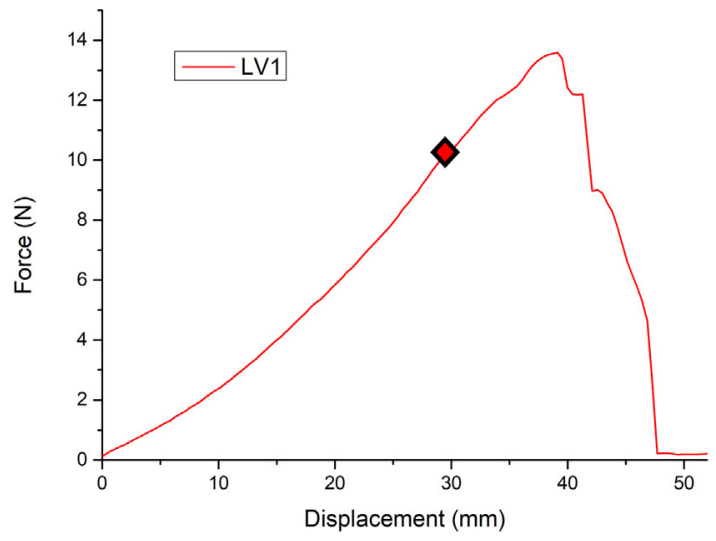

Table 2

Summary of mean thickness and rupture strength from left ventricle samples.

\begin{tabular}{llll} 
Specimen $(\mathrm{N}=6)$ & & Mean thickness $(\mathrm{mm})$ & Rupture strength $(\mathrm{N})$ \\
\hline Left Ventricle & 1 & 12.8 & 10.82 \\
& 2 & 14.8 & 16.31 \\
& 3 & 15.1 & 14.29 \\
& 4 & 13.7 & 13.47 \\
& 5 & 16.4 & 15.99 \\
Mean & 6 & 16.5 & 21.71 \\
Standard Deviation & & 14.88 & 15.43 \\
Correlation & & 1.463 & 3.658 \\
& & $\mathrm{R}^{2}=0.7131$ & \\
\end{tabular}

illustrated in Fig. 6 b.

\subsection{Numerical simulation of a U-suture on the left ventricle}

In order to validate our numerical simulation, comparison was made between the experimental response from suture tensile tests and the numerical response. Increasing displacement along the Y-axis was applied in the FE model at the top of the suture, reproducing the equivalent mechanical experiment. Imposed displacement was of $25 \mathrm{~mm}$ over the entire simulation time. Numerical simulation started to show instability induced by large strain at $50 \%$ of the simulation and was stopped at $75 \%$. Therefore, we chose to use a value of $t$ (percentage of achieved simulation) of 0.5 (with $d=12.64 \mathrm{~mm}$; $R F=10.67 \mathrm{~N}$ ) as our simulation end.

\section{(b) \\ Correlation between rupture strength and thickness}

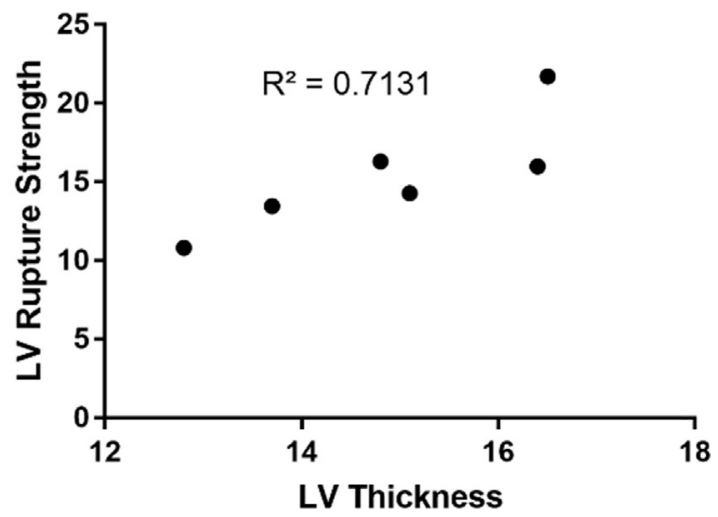

Fig. 6. (a) Typical load-displacement curve from suture test. (b) Correlation between ventricle rupture threshold and thickness. 

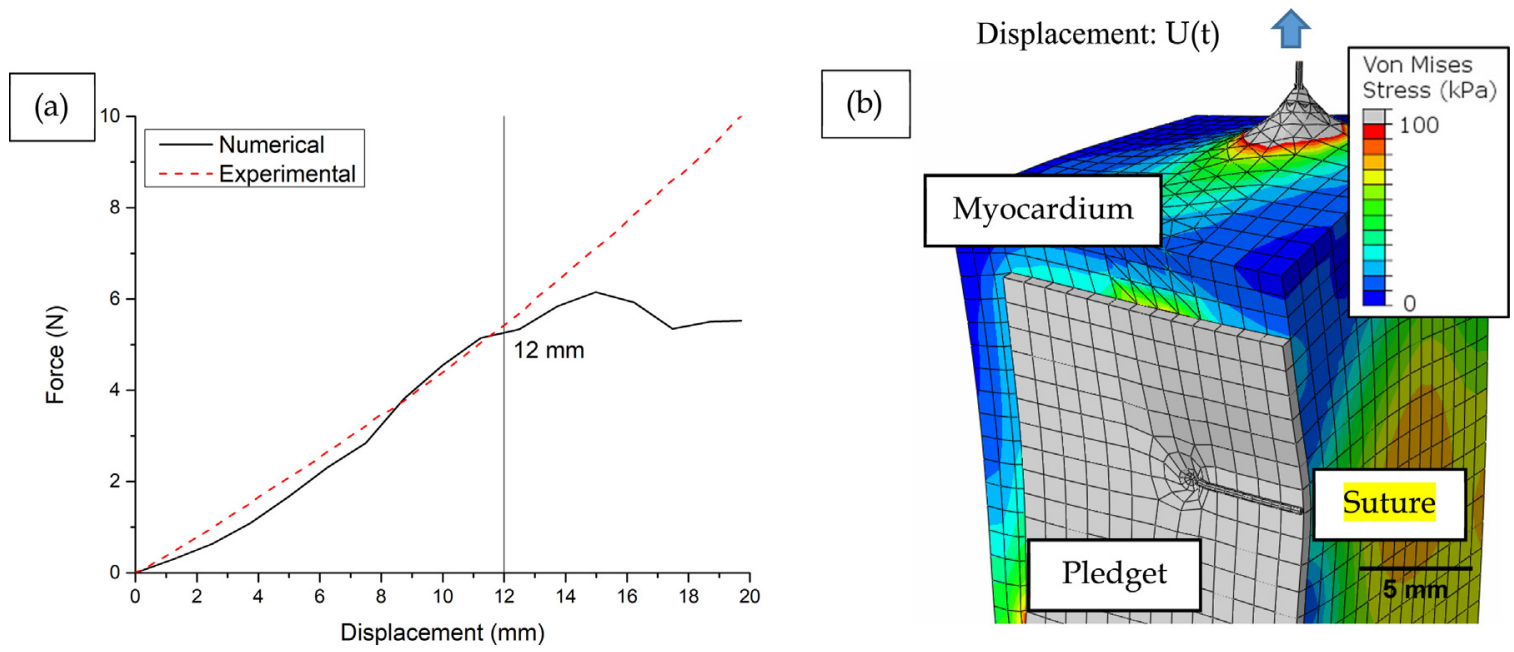

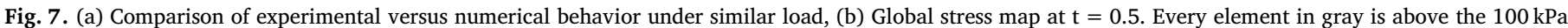
threshold.

Fig. 7a. shows a good match between the model and the experiment, therefore validating the reliability of our model. The maximal error remains under $0.5 \mathrm{~N}$ and the prediction remains correct until a displacement as large as $12 \mathrm{~mm}$. For larger displacement, discrepancy occurs, and the simulation is not to be considered beyond this limit.

Assessment of the reliability was confirmed by looking at the peak stress (von Mises) inside model parts as shown in Table 3. Using failure stress data of 48 and $493 \mathrm{MPa}$ for the pledget and suture respectively (Naleway et al., 2015; ASM International, 2009), we assessed that stresses remain in the elastic domain for the elastic parts.

Simulation results showed expected stress concentration at the suture entry and exit point of the myocardium as illustrated in Figs. 7.b and 8.b. Despite a low friction coefficient (0.005 from (Rawson et al., 2015)), we observed a movement of the surface near the suture at the top of the model.

Fig. 8 shows the stress field and the stress triaxiality for the maximal displacement achieved with this model. Stress sharply decreased as a function of the distance from the suture point in each direction. For a distance further than $1 \mathrm{~mm}$, the equivalent von Mises stress stabilized around $50 \mathrm{kPa}$, which was below the previously defined threshold $(100 \mathrm{kPa})$. The tissue close to the hole exhibited stress larger than the threshold and was visible at the center (Fig. 8b).

The stress triaxiality factor map on Fig. $8 \mathrm{c}$ illustrates the type of mechanical loading. At the wire location, shear stress was predominant. The elements located farther from the entry point, the predominant stress turned to compression. For larger distances, the loading became gradually complex with a combination of shear and tensile strength.

\section{Discussion}

This study allowed us to extract two major findings that are (1) the ability to run a numerical model of the left ventricle tissue and (2) a computer-calculated threshold of $2 \mathrm{~mm}$ for the space between two adjacent sutures into the myocardium.

Table 3

Maximum stress (von Mises) inside elastic model parts compared to literature references.

\begin{tabular}{lll}
\hline Part & Pledget & Suture \\
\hline Maximum stress & $44 \mathrm{MPa}$ & $399 \mathrm{MPa}$ \\
$\begin{array}{c}\text { Literature failure } \\
\text { stress }\end{array}$ & $\begin{array}{l}48 \mathrm{MPa} \text { (ASM International, } \\
\text { 2009) }\end{array}$ & $\begin{array}{l}493 \mathrm{MPa} \text { (Naleway et al., } \\
\text { 2015) }\end{array}$ \\
\hline
\end{tabular}

\subsection{Model validation and limitations}

Numerous numerical and finite element models of the heart or the myocardium are described in the literature; however, the overwhelming majority are either highly specific to a region (Hassan et al., 2012), or complex to reproduce due to the use of a custom material law, for instance (Huyghe et al., 1991). Material constitutive law with a higher level of complexity could enhance the reliability of simulation data but undoubtedly at a higher computational and experimental cost. The methodology and parameters described in this paper are meant to overcome such complexities by providing everything needed to run our model. The use of a widespread FEA package (ABAQUS, SIMULIA) and a built-in constitutive law are a way to provide a straightforward approach to left myocardium finite element analysis.

With the help of this Finite Element model, we investigated the stress concentrations occurring in the case of a LVAD suture on the left myocardium. The method used to fit experimental data of tensile strength to a stable hyperelastic law proved its efficiency. Indeed, as observed in the work of Forsell and Gasser (2011) on ventricle penetration, parameter identification from tensile trials is a commonly used technique. In our model, a reduced polynomial law of second order provided a sufficient degree of complexity to simulate the myocardium behavior for a suture displacement up to $12 \mathrm{~mm}$.

Indeed, good correlation was found while comparing experimental suture data on left myocardium to the generated numerical model with an error of less than $0.5 \mathrm{~N}$ in this domain of interest. The previous study on tendon suture reported by Rawson et al. (2015) allowed them to highlight the good correlation that may be achieved between experiments and simulation as well as the predictive power of such numerical tools. In a similar way, the generation of simulated stress maps allowed us to confirm the reliability of our model and to extensively investigate the influence of the suture on the tissue. This is to our knowledge the first numerical simulation of left myocardial suture. This work reinforces the impact of finite element analysis when used to study surgical techniques.

When juxtaposing experimental and numerical results, we observed that mechanical suture trials were not able to provide as many parameters as the simulation does. Despite a robust methodology, the biological nature of the samples showed some variability (Fig. 5.b) that may restrict a reliable analysis. The use of a constitutive law identified on a mean response of the tissue allows us to overcome this variability. One of the major strengths of the model is its ability to reproduce identical boundary conditions without the influence of the experimental setup. 


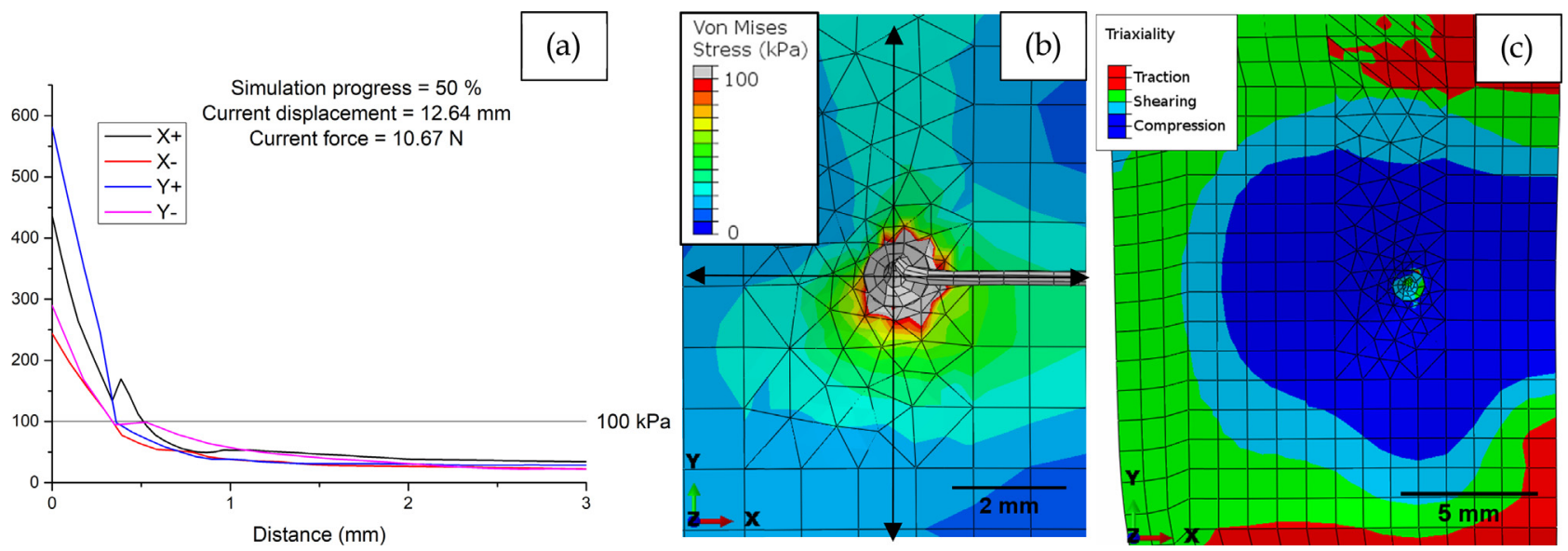

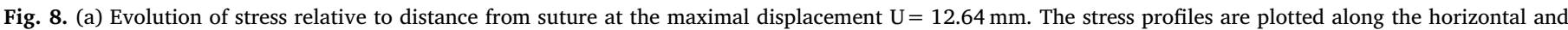

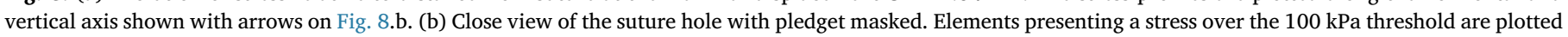
in gray. (c) Triaxiality of stress is a new data type available with FEM.

This numerical model should be considered with respect to its limitations and the assumptions that were adopted. Myocardium behavior is known to be highly anisotropic. An interesting way to improve numerical simulation would be to take in account fiber orientations as described in previous studies (Lombaert et al., 2012; Rohmer et al., 2007). The visco-elastic or visco-hyperelastic behavior is also a planned improvement for this kind of FE simulation, as it would enable a timerelated approach of the tissue response. However, it is important to keep in mind that the balance between model complexity and computational cost is a critical parameter for simulation studies. The suture knot was not modelled, yet this is often the failure location of suture repairs (Naleway et al., 2015); however, our study focused on the stress in the myocardium tissue and not the suture itself, which would not be affected by this simplification.

Large deformations (observed above $12 \mathrm{~mm}$ of displacement in the present model) could not be studied in our simulations. Nevertheless, this limitation emerges from numerical instabilities of the finite element solver. This issue could be overcome by implementing damage behavior inside the model and/or ventricular failure simulation (Forsell and Gasser, 2011).

\subsection{Contribution of the model for myocardial suture assessment}

Beyond the performance of our model, the major impact of this study is the emergence of a numerical threshold for suture spacing (Fig. 6a). We were able to study stresses inside model elements in multiple directions from the suture entry point. We confirmed the occurrence of high stress next to the suture entrance in each of 4 directions $(+\boldsymbol{X},-\boldsymbol{X},+\boldsymbol{Y},-\boldsymbol{Y})$. Moreover, we witnessed a rapid decrease in this stress as we looked further from the suture entrance. Almost no residual stress was observed further than one millimeter away from the entry point, as shown on Fig. 8a, even at the highest achievable displacement.

This limit was found to be equal to four times the suture diameter ( $0.24 \mathrm{~mm}$ in that case). This is the first step of a diameter-distance relationship for designing more secure and efficient heart sutures. These results encouraged us to define a minimum space of $2 \mathrm{~mm}$ between consecutive sutures to avoid stress overlap. However, precautions must be taken with this suggested threshold. This result may not be relevant for another suture thread, technique or on right ventricle myocardium.

Despite the existence of clinical studies on LVAD implantation (Seyfarth et al., 2008; Bernhardt et al., 2015), no guidelines for the myocardial suture based on a numerical model could be found. The work presented by presented by Charitos and Sievers (2010) on a modified technique for LVAD implantation is a good example of what is usually found in the literature. As they present their methodology, they do not elaborate on the minimum spacing of $2.5 \mathrm{~mm}$ between two pledgeted U-suture that they recommend. Nevertheless, our numerical threshold is in good agreement with the LVAD implantation technique presented in their study.

In the work of Hanke et al. (2016), the evaluation of four suture techniques is proposed for LVAD implantation. Whilst highlighting the crucial role of the suture technique, their methodology was only based on a visual examination and measurements of sutures on silicon dummies. Despite a relevant comparison of these techniques, no quantitative data are provided on stress concentrations whereas the evaluation of different suture techniques for LVAD implantation was the main topic.

We anticipate that surgical guidelines may benefit from numerical simulations to assess the best practices for suture placement. This approach falls within the current framework delimited by the FDA for medical device certification (Morrison et al., 2017; Malinauskas et al., 2017) but also fully respects the 3 R's guidelines on animal studies (Bratcher and Reinhard, 2015).

Further work will also aim to extend the model's applications. Thus, several sutures could be evaluated and compared, therefore providing a better understanding of stresses occurring in LVAD implantation.

\section{Conclusions}

The proposed model gives access to an enhanced understanding of stresses and strains occurring during U-suture solicitation on the left myocardium. Uniaxial tensile trials were used to identify the mechanical behavior of left ventricle samples. The key-findings of the paper are (i) the identification of an hyperelastic reduced polynomial constitutive law for left myocardial tissue, (ii) the establishment of a finite element model accurately reproducing the global behavior described through mechanical suture assessment and (iii) the definition of a minimal suture spacing of $2 \mathrm{~mm}$ between adjacent $\mathrm{U}$-sutures on the left myocardium.

The present work complies well with the current context of animal use reduction ( 3 R's guidelines) and with the inclusion of simulation work into the process of medical device certification (FDA guidelines). Anticipated applications are about designing more efficient and secure LVAD suture techniques and testing them with a numerical predictive approach.

\section{Acknowledgment}

This research did not receive any specific grant from funding 
agencies in the public, commercial, or not-for-profit sectors.

\section{References}

ASM International, 2009. Materials and Coatings for Medical Devices: Cardiovascular. ASM International, OH, USA.

Baillargeon, B., Rebelo, N., Fox, D.D., Taylor, R.L., Kuhl, E., 2014. The Living Heart Project: A robust and integrative simulator for human heart function. European. J. Mech. A/Solids, Front. Finite Deform. Electromec. 48, 38-47. http://dx.doi.org/10 1016/j.euromechsol.2014.04.001.

Bernhardt, A.M., By, T.M.M.H.D., Reichenspurner, H., Deuse, T., 2015. Isolated permanent right ventricular assist device implantation with the heartware continuous-flow ventricular assist device: first results from the European registry for patients with mechanical circulatory support. Eur. J. Cardiothorac. Surg. 48, 158-162. http://dx. doi.org/10.1093/ejcts/ezu406.

Bratcher, N.A., Reinhard, G.R., 2015. Creative implementation of 3Rs principles within industry programs: beyond regulations and guidelines. J. Am. Assoc. Lab. Anim. Sci. 54, 133-138.

Braunwald, E., 2013. Heart failure. JCHF 1, 1-20. http://dx.doi.org/10.1016/j.jchf.2012. 10.002 .

Bui, A.L., Horwich, T.B., Fonarow, G.C., 2011. Epidemiology and risk profile of heart failure. Nat. Rev. Cardiol. 8, 30-41. http://dx.doi.org/10.1038/nrcardio.2010.165.

Charitos, E.I., Sievers, H.-H., 2010. A modified suturing technique for the implantation of the apical cannula of the HeartMate II left ventricular assist device. Interact CardioVasc. Thorac. Surg. 11, 393-394. http://dx.doi.org/10.1510/icvts.2010. 244509.

Forsell, C., Gasser, T.C., 2011. Numerical simulation of the failure of ventricular tissue due to deep penetration: The impact of constitutive properties. J. Biomech. 44, 45-51. http://dx.doi.org/10.1016/j.jbiomech.2010.08.022.

Go, A.S., Mozaffarian, D., Roger, V.L., Benjamin, E.J., Berry, J.D., Blaha, M.J., Dai, S., Ford, E.S., Fox, C.S., Franco, S., Fullerton, H.J., Gillespie, C., Hailpern, S.M., Heit, J.A., Howard, V.J., Huffman, M.D., Judd, S.E., Kissela, B.M., Kittner, S.J., Lackland, D.T., Lichtman, J.H., Lisabeth, L.D., Mackey, R.H., Magid, D.J., Marcus, G.M., Marelli, A., Matchar, D.B., McGuire, D.K., Mohler, E.R., Moy, C.S., Mussolino, M.E., Neumar, R.W., Nichol, G., Pandey, D.K., Paynter, N.P., Reeves, M.J., Sorlie, P.D., Stein, J., Towfighi, A., Turan, T.N., Virani, S.S., Wong, N.D., Woo, D., Turner, M.B., 2014. Heart disease and stroke statistics-2014 update. Circulation 129, e28-e292. http://dx.doi.org/10.1161/01.cir.0000441139.02102.80.

Hanke, J.S., Krabatsch, T., Rojas, S.V., Deniz, E., Ismail, I., Martens, A., Shrestha, M. Haverich, A., Netuka, I., Schmitto, J.D., 2016. In vitro evaluation of inflow cannula fixation techniques in left ventricular assist device surgery: thoughts and progress. Artif. Organs. http://dx.doi.org/10.1111/aor.12735.

Hassan, M.A., Hamdi, M., Noma, A., 2012. The nonlinear elastic and viscoelastic passive properties of left ventricular papillary muscle of a Guinea pig heart. J. Mech. Behav.Biomed. Mater. 5, 99-109. http://dx.doi.org/10.1016/j.jmbbm.2011.08.011.

Heidenreich, P.A., Albert, N.M., Allen, L.A., Bluemke, D.A., Butler, J., Fonarow, G.C., Ikonomidis, J.S., Khavjou, O., Konstam, M.A., Maddox, T.M., Nichol, G., Pham, M., Piña, I.L., Trogdon, J.G., 2013. Forecasting the impact of heart failure in the United States. Circ. Heart Fail 6, 606-619. http://dx.doi.org/10.1161/HHF Ob013e318291329a.

Horowitz, A., Perl, M., Sideman, S., Ritman, E., 1986. Comprehensive model for the simulation of left ventricle mechanics. Med. Biol. Eng. Comput. 24, 150-156. http:// dx.doi.org/10.1007/BF02443928.

Humphrey, J.D., Strumpf, R.K., Yin, F.C., 1990a. Biaxial mechanical behavior of excised ventricular epicardium. Am. J.Physiol. Heart. Circ. Physiol. 259, H101-H108.

Humphrey, J.D., Strumpf, R.K., Yin, F.C.P., 1990b. Determination of a constitutive relation for passive myocardium: Ii.-parameter estimation. J. Biomech. Eng. 112, $340-346$.

Huyghe, J.M., van Campen, D.H., Arts, T., Heethaar, R.M., 1991. The constitutive behaviour of passive heart muscle tissue: a quasi-linear viscoelastic formulation. J. Biomech. 24, 841-849.

Katz, J., Milliken, M.C., Stray-Gundersen, J., Buja, L.M., Parkey, R.W., Mitchell, J.H., Peshock, R.M., 1988. Estimation of human myocardial mass with MR imaging.
Radiology 169, 495-498. http://dx.doi.org/10.1148/radiology.169.2.2971985.

Lin, D.H.S., Yin, F.C.P., 1998. A multiaxial constitutive law for mammalian left ventricular myocardium in steady-state barium contracture or tetanus. J. Biomech. Eng. 120, 504-517.

Lombaert, H., Peyrat, J.M., Croisille, P., Rapacchi, S., Fanton, L., Cheriet, F., Clarysse, P., Magnin, I., Delingette, H., Ayache, N., 2012. Human atlas of the cardiac fiber Architecture: study on a healthy population. IEEE Trans. Med. Imaging 31, 1436-1447. http://dx.doi.org/10.1109/TMI.2012.2192743.

Malinauskas, R.A., Hariharan, P., Day, S.W., Herbertson, L.H., Buesen, M., Steinseifer, U., Aycock, K.I., Good, B.C., Deutsch, S., Manning, K.B., Craven, B.A., 2017. FDA benchmark medical device flow models for CFD validation. ASAIO J. 63, 150-160. http://dx.doi.org/10.1097/MAT.0000000000000499.

Morrison, T.M., Dreher, M.L., Nagaraja, S., Angelone, L.M., Kainz, W., 2017. The role of computational modeling and simulation in the total product life cycle of peripheral vascular devices. J. Med. Devices 11, 024503-024503-5. http://dx.doi.org/10.1115/ 1.4035866 .

Naleway, S.E., Lear, W., Kruzic, J.J., Maughan, C.B., 2015. Mechanical properties of suture materials in general and cutaneous surgery. J. Biomed. Mater. Res. 103, 735-742. http://dx.doi.org/10.1002/jbm.b.33171.

Nash, M.P., Hunter, P.J., 2000. Computational mechanics of the heart. J. Elast. Phys. Sci. Solids 61, 113-141.

Paez, J.M.G., Martin, A.C.S., Sestafe, J.V.G., Jorge-Herrero, E., Millán, I., Navidad, R., Cordón, A., Castillo-Olivares, J.L., 1994. Resistance and elasticity of the suture threads employed in cardiac bioprostheses. Biomaterials 15, 981-984. http://dx.doi org/10.1016/0142-9612(94)90078-7.

Pinto, J.G., Fung, Y.C., 1973. Mechanical properties of the heart muscle in the passive state. J. Biomech. 6, 597-616.

Rawson, S.D., Margetts, L., Wong, J.K.F., Cartmell, S.H., 2015. Sutured tendon repair; a multi-scale finite element model. Biomech. Model Mechanobiol. 14, 123-133. http:// dx.doi.org/10.1007/s10237-014-0593-5.

Rogers, J.G., Aaronson, K.D., Boyle, A.J., Russell, S.D., Milano, C.A., Pagani, F.D. Edwards, B.S., Park, S., John, R., Conte, J.V., Farrar, D.J., Slaughter, M.S., HeartMate II Investigators, 2010. Continuous flow left ventricular assist device improves functional capacity and quality of life of advanced heart failure patients. J. Am. Coll. Cardiol. 55, 1826-1834. http://dx.doi.org/10.1016/j.jacc.2009.12.052.

Rohmer, D., Sitek, A., Gullberg, G.T., 2007. Reconstruction and visualization of fiber and laminar structure in the normal human heart from ex vivo diffusion tensor magnetic resonance imaging (DTMRI) data. Invest. Radiol. 42, 777-789. http://dx.doi.org/10. 1097/RLI.0b013e3181238330.

Sermesant, M., Delingette, H., Ayache, N., 2006. An electromechanical model of the heart for image analysis and simulation. IEEE Trans. Med. Imaging 25, 612-625. http://dx. doi.org/10.1109/TMI.2006.872746.

Seyfarth, M., Sibbing, D., Bauer, I., Fröhlich, G., Bott-Flügel, L., Byrne, R., Dirschinger, J., Kastrati, A., Schömig, A., 2008. A randomized clinical trial to evaluate the safety and efficacy of a percutaneous left ventricular assist device versus intra-aortic balloon pumping for treatment of cardiogenic shock caused by myocardial infarction. J. Am. Coll. Cardiol. 52, 1584-1588. http://dx.doi.org/10.1016/j.jacc.2008.05.065.

Smith, N., de Vecchi, A., McCormick, M., Nordsletten, D., Camara, O., Frangi, A.F., Delingette, H., Sermesant, M., Relan, J., Ayache, N., Krueger, M.W., Schulze, W.H.W., Hose, R., Valverde, I., Beerbaum, P., Staicu, C., Siebes, M., Spaan, J., Hunter, P., Weese, J., Lehmann, H., Chapelle, D., Rezavi, R., 2011. euHeart: personalized and integrated cardiac care using patient-specific cardiovascular modelling. Interface Focus 1, 349-364. http://dx.doi.org/10.1098/rsfs.2010.0048.

Sommer, G., 2013. Biomechanical properties of the human ventricular myocardium. Biomed. Tech. 58. http://dx.doi.org/10.1515/bmt-2013-4108.

Stevens, C., Hunter, P.J., 2003. Sarcomere length changes in a 3D mathematical model of the pig ventricles. Prog. Biophys. Mol. Biol. Mechano-Electric. Feedback and Cardiac Arrhythm. 82, 229-241. http://dx.doi.org/10.1016/S0079-6107(03)00023-3.

Stewart, G.C., Givertz, M.M., 2012. Mechanical circulatory support for advanced heart failure. Circulation 125, 1304-1315. http://dx.doi.org/10.1161/CIRCULATIONAHA. 111.060830 .

Vinnakota, K.C., Bassingthwaighte, J.B., 2004. Myocardial density and composition: a basis for calculating intracellular metabolite concentrations. Am. J. Physiol. Heart Circ. Physiol. 286, H1742-H1749. http://dx.doi.org/10.1152/ajpheart.00478.2003. 